\title{
DISCURSOS EN EL PAISAJE ANDINO COLONIAL: REFLEXIONES EN TORNO A LA DISTRIBUCIÓN DE SITIOS CON ARTE RUPESTRE COLONIAL EN TARAPACÁ*
}

\author{
DISCOURSES IN THE COLONIAL ANDEAN LANDSCAPE: \\ REFLECTIONS ON THE DISTRIBUTION OF SITES WITH COLONIAL \\ ROCK ART IN TARAPACA
}

Bosco González Jiménez**

\begin{abstract}
En este articulo se reflexiona sobre la importancia de la utilización de sistemas de comunicación visual andinos coloniales como fuente de información valida, que en conjunto y en un mismo estatuto que las fuentes escritas, nos permiten reflexionar sobre el pasado prehispánico y colonial de las sociedades andinas en general y específicamente sobre las dinámicas sociopolíticas locales existentes en Tarapacá entre los siglos XVI y XVII.

Para nutrir y problematizar este planteamiento, se exhibe un análisis descriptivo y distribucional de los sitios de arte rupestre en Tarapacá que contienen motivos coloniales en su interior. Para ello se exponen las frecuencias de presentación de estos motivos agrupados en un total de 11 sitios identificados para todo Tarapacá, sitios que a la vez son aglomerados en torno a categorías construidas a partir de antecedentes etnohistóricos referidos a la división administrativa de lo que fue la doctrina de Tarapacá en los siglos XVI y XVII.
\end{abstract}

Palabras claves: Arte rupestre colonial, Tarapacá, evangelización, discursos indígenas, dispositivos de comunicación visual.

This paper considers the importance of the use of colonial Andean visual communication systems as a valid source of information, which together and when given the same status as written sources, allow us reflect on the pre-Hispanic and colonial Andean societies' past in general and reflect specifically on the local socio-political dynamics in Tarapacá between the sixteenth and seventeenth centuries.

To nurture and problematize this approach, this paper gives a descriptive analysis of rock art sites in Tarapaca and the colonial motifs inside. To do this the frequencies of these motifs are grouped into a total of 11 sites identified in Tarapacá. These sites are systematized into categories constructed from ethnohistorical records relating to the administrative division of what was the Parish of Tarapaca in the sixteenth and seventeenth centuries.

Key words: Colonial rock art, Tarapaca, evangelization, indigenous discourses, visual communication devices.

\section{Introducción}

Integrar nuevos soportes y dispositivos de comunicación al análisis del pasado prehispánico y colonial de las sociedades andinas ha venido siendo, en las últimas décadas, una de las grandes preocupaciones de diversos investigadores vinculados al estudio del pasado prehispánico y colonial de las sociedades andinas; estos investigadores han utilizado como fuentes etnohistóricas diversos soportes como lo son: Quipus (Urton, 1997, 2003 y 2005, Salomon, 1994, 1997, 2005 y 2006), Queros (Cummins, 1995, 2004; Martínez, 20013 y 2014 y Mulvani, 2004) y arte rupestre colonial (Arenas 2007, 2009, 2011, 2013 a y b; Gallardo et al., 1990; Hosting, 2007; Martínez, 2009, 2011, 2013 y Strecker, 1993) entre otros soportes.
La valoración y utilización de los sistemas de comunicación visual mencionados no es solo una cuestión metodológica, responde a un interés por dotar de visibilidad a una diversidad mayor de discursos, dado que el carácter hegemónico, selectivo y excluyente de la escritura (Foucault, 1992 y 2002) en sociedades donde esta es poco difundida (Goody, 1998) hace que sea necesario el uso de otras fuentes de formalización para acceder a una diversidad mayor de discursos sociales. Respecto de esto José Luis Martínez (2013 y 2014) plantea la importancia de construir un conocimiento que integre lo oral, lo visual, lo táctil, en fin, esas otras formas de registro y comunicación, junto con lo escrito, de manera tal que la escritura deje de ser la dominante y quede en la posición de un tipo de conocimiento específico,

\footnotetext{
* Agradecimientos Convenio de Desempeño UTA-MINEDUC.

** Programa de Doctorado de la Universidad de Chile. Correo electrónico: boscogonzalezj@yahoo.es
} 
pero no el único o más importante (Martínez et al., 2014: 92)

Asumiendo la necesidad de desarrollar investigaciones que se orienten por la perspectiva señalada y agregando a ello mi interés por la continuidad de la producción y circulación de sistemas de comunicación visual de origen prehispánicos durante la colonia es que en el presente artículo se desarrolla una reflexión sobre la distribución de los sitios con arte rupestre colonial en Tarapacá, para ver si esta nos puede señalar algunos caminos de reflexión respecto de las políticas de evangelización y la respuesta de los indígenas a estas durante la colonia, dado que la distribución que se ha podido detectar hasta ahora es bastante insinuante.

Junto con ello se presenta una reflexión sobre la importancia que adquiere el concepto de coexistencias discursivas para reflexionar sobre la forma en que las dinámicas de interacción entre indígenas y españoles se formalizaron en los antiguos sistemas de comunicación visuales andinos y en la forma en que estos circularon en el espacio físico, que más allá de ser una referencia física material, es un espacio socialmente construido (Bonnemaison, 2004).

\section{Coexistencias sociopolíticas e integración de significantes andinos y europeos}

Si pensamos de forma mecánica podríamos afirmar que la incorporación de significantes europeos en los sistemas de comunicación visual andinos obedece a procesos de imposición absoluta de parte de los discursos occidentales sobre los discursos y soportes de comunicación indígenas, pero esto no fue necesariamente así, muchas veces los sistemas de comunicación visuales de origen prehispánicos operantes durante la colonia refirieron a una diversidad discursiva y significante, siendo la expresión de contradicciones desarrolladas en el seno de las sociedades andinas coloniales, y por sobre todo, manifestaron diversas formas de coexistencia significante referida a discursos sociales simultáneos, con una determinada forma de abordar la interpretación y producción subjetiva del otro.

Esto es posible de evidenciar en diversos tipos de soportes, visuales, auditivos, etc. Para el caso de Tarapacá existen investigaciones que plantean la conformación de autoridades religiosas locales que habrían oficiado ceremonias y festividades, lo cual nos remite a la posibilidad de la formación de autoridades espirituales locales (Díaz, 2011) o instituciones intermedias como es el caso de las cofradías (Díaz et al., 2014) que habrían operado en un espacio de legitimidad entre la base social indígena y las autoridades formales católicas, lo cual nos remite a soportes rituales capaces de hacer converger discursos indígenas y católicos, donde lo visual y lo auditivo convergen como mecanismos de formalización de dichos discursos.

Cuando observamos el arte rupestre colonial es posible pensar en los mismos términos, nos encontramos con un soporte de comunicación que continúa operando y que logra integrar aspectos tanto cristianos como indígenas en sus soluciones visuales, donde los indígenas habrían incorporado selectivamente (Martínez et al., 2009, 2011 y 2013) significantes católicos y europeos en general.

La forma en que se dispusieron los significantes europeos en los contextos representativos de origen prehispánicos nos puede hablar de ello. Podemos ver como en algunos casos los significantes europeos se añadieron como un actor que no interviene totalmente las composiciones preexistentes. $\mathrm{Si}$ observamos el Quero colonial que se muestra en la Figura 1 podemos ver que el espacio significado está debidamente segmentado en tres niveles donde los referentes europeos como los ángeles, equinos y jinetes están integrados al contexto representacional general, sin alterar los motivos prehispánicos y el contexto general.

Algo similar ocurre con algunos de los motivos rupestres coloniales que me ha tocado observar en Tarapacá, en muchos de ellos se hace evidente una interacción y coexistencia solidaria ${ }^{1}$ entre los

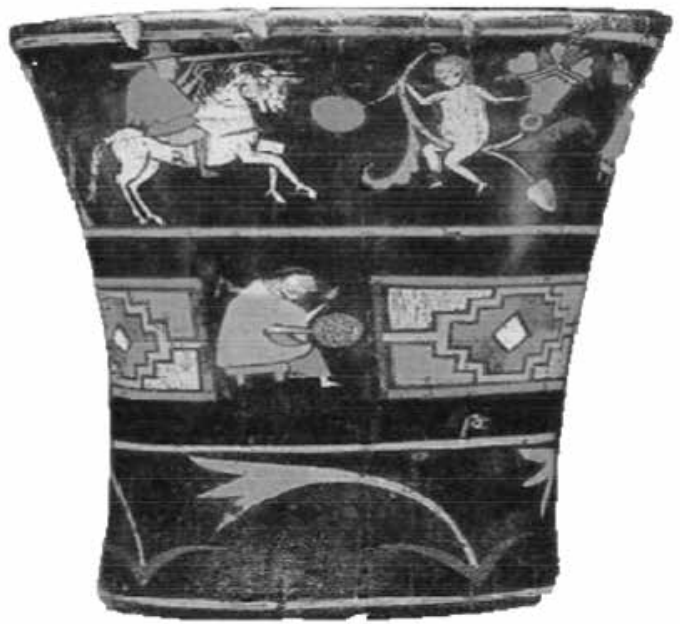

Figura 1. Quero colonial con iconografía prehispánica y europea. Referencia. Cummins, Thomas 1993. 
referentes prehispánicos y europeos. En las Figuras 2 y 3 correspondientes a petroglifos existentes en el sitio Chillaiza II ubicada en la quebrada de Camiña del norte grande de Chile, se puede observar la manera en que interactúan cruces latinas con significantes prehispánicos sin que los motivos religiosos se orienten a descomponer completamente los espacios significados, lo cual podría expresar una solidaridad sincrónica (Martínez et al., 2009, 2011 y 2013) entre los significantes en los espacios significados.

También es posible identificar casos en que la integración del significante europeo altera e invisibiliza la presencia de los discursos y los referentes prehispánicos, es decir, casos en que esta coexistencia posee un carácter antagónico e iconoclasta (Strecker, 1993).

En primera instancia podríamos sostener que estos referentes habrían sido introducidos de forma intencional por las autoridades eclesiásticas y administrativas de la colonia, como es el caso del arte rupestre colonial del sector de Espinar en Cuzco (Hosting, 2007) con la finalidad de "evidenciar la supuesta superioridad de la religión católica y cumplieron un papel de exorcismo en el marco de las campañas de extirpación de idolatría. $\mathrm{Su}$ realización sobre obras difíciles de construir correspondió a una medida preconizada por los españoles para purificar los sitios y esconder las imágenes paganas" (Duviols, 1977; 297-298).

Alberto Díaz y Juan Chacama (2012) comentan como el arte rupestre habría sido considerado por los europeos como la expresión de actividades y pensamientos infieles e idolátricos, quienes citando el relato de la testigo María Juana, el que se encuentra registrado en "Visita de idolatría hecha en Checras y Andajes por el cura de la doctrina de Paccho, doctor don Pedro de Celis. Cajatambo 1725" (García 1994:497 en Díaz y Chacama, 2012: 72).

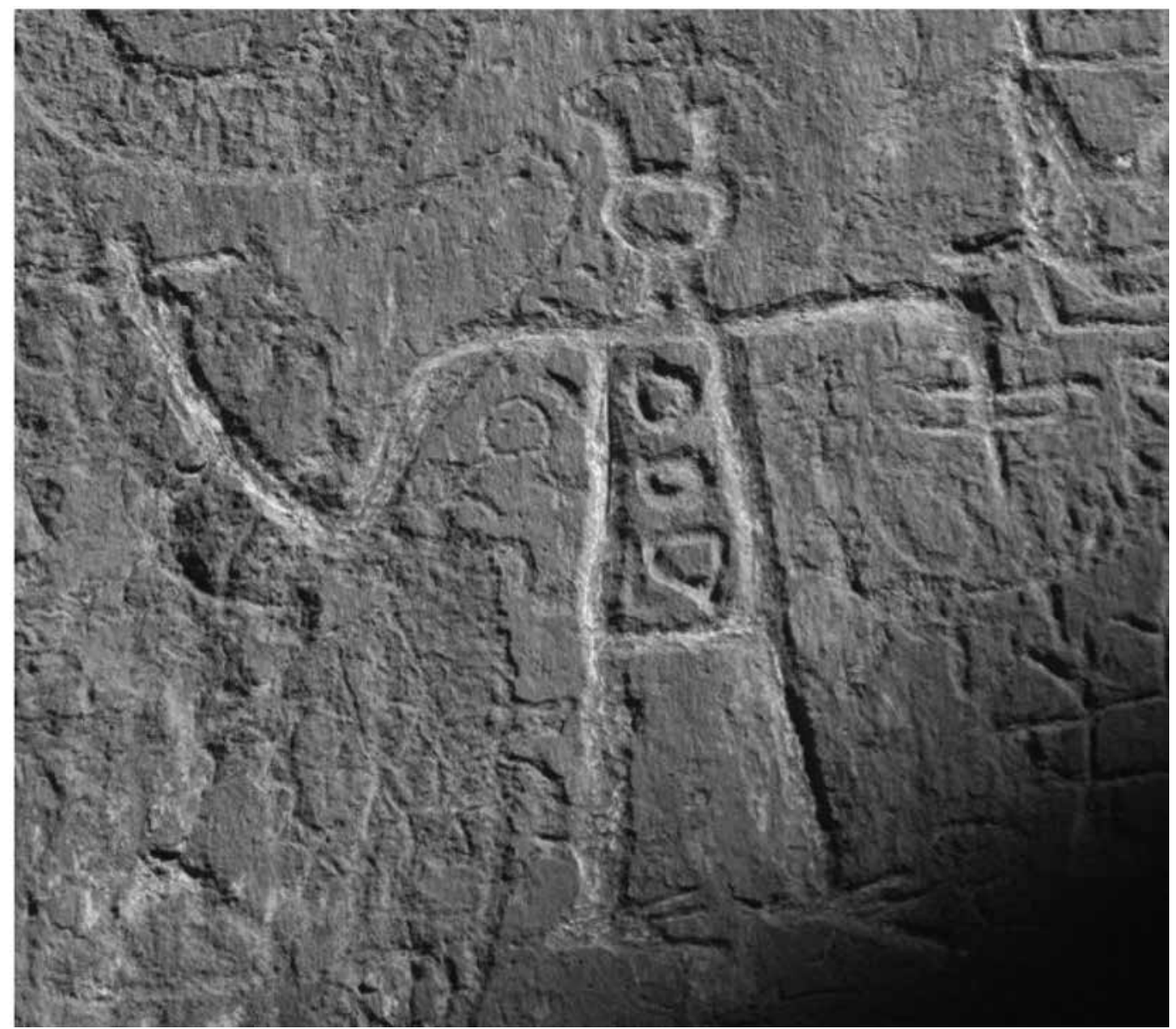

Figura 2. Petroglifo colonial. Se representa un antropomorfo con cruces latinas en sus extremidades superiores, sitio Chillaiza II. Quebrada de Camiña. Foto: Bosco González Jiménez. 


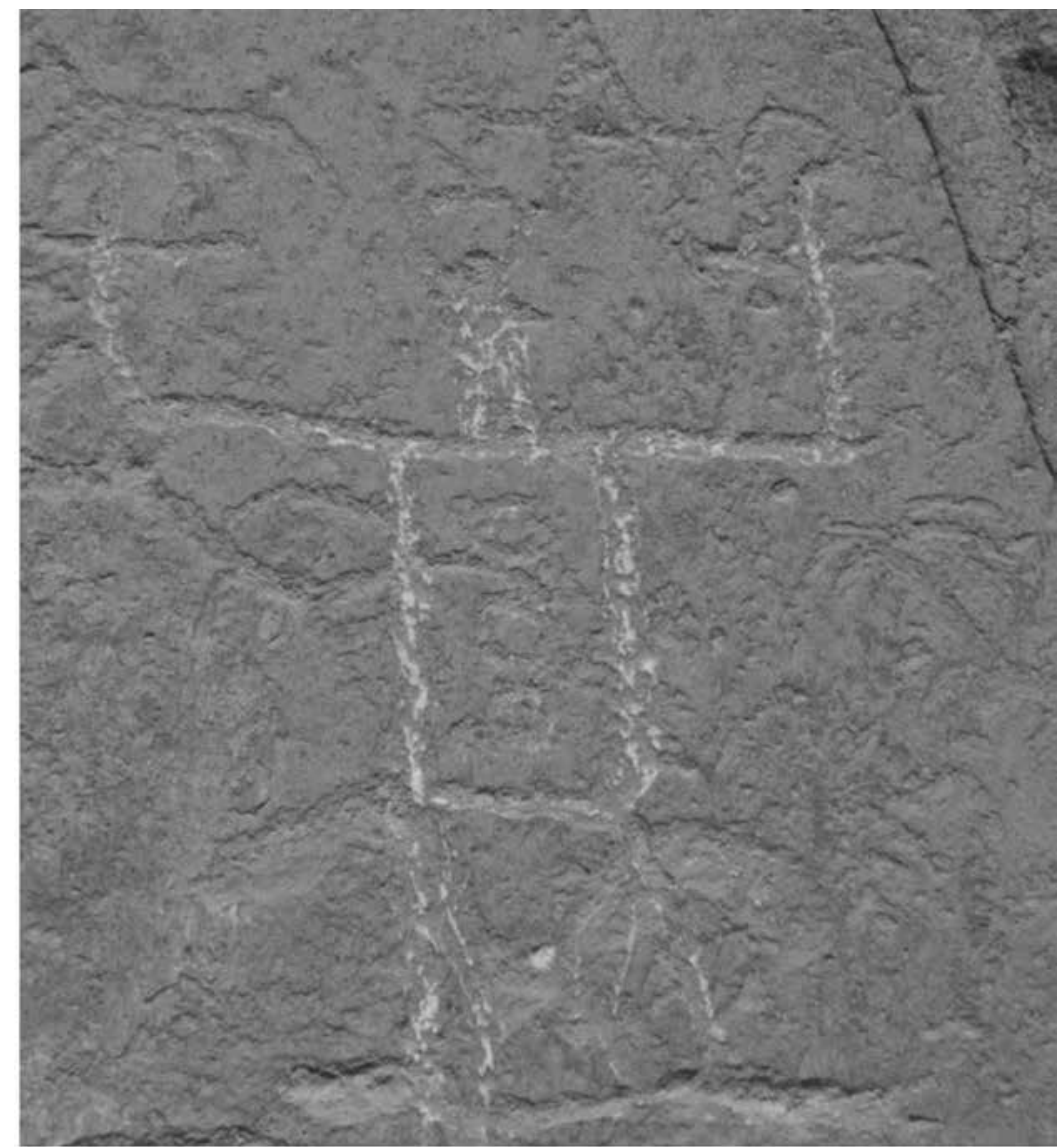

Figura 3. Petroglifo colonial. Se representa un antropomorfo con cruces latinas en sus extremidades superiores ubicado en el sitio Chillaiza II. Quebrada de Camiña. Foto: Bosco González Jiménez.

"...y que para descargo de su conciencia deçia que en el serro nombrado San Cristoval dos cuadras de distancia deste pueblo en una peña viva estaba pin[ta]do un hidolo en forma de llama a el qual iban todos sus maiores a dar adoración (...) Y buelto a preguntar que serimonias usavan sus maiores que iban a mochar a dicha guaca respondió que antiguamente a los viejos hablava i cada uno pediapor medio del llacha lo que neçeçitaba pero que todo les salia en contra y que porque la dicha guaca era semejante a una llama no avia quedado ninguna en su pueblo por donde conoçia que era castigo de Dios".

En la misma visita, el testigo Juan Bautista indica que:

"Y bueltole a preguntar si tenía muchos disipulos respondio que con la peste se avian muerto los mas y que la dicha Maria Quillai y Juan Pito mochavan con el (...) $Y$ preguntandole que usavan quando iban a mochar dijo que en la dicha guaca como se estava viendo avian varias pintura de hombres y mugeres y que cogiendo cada uno en su mente a la que le pareçia iba a pedir allí”.

Por otro lado podemos encontrarnos con situaciones en donde los significantes europeos habrían sido apropiados selectivamente por parte de la población nativa, especialmente la cruz, lo que habría llevado a la formación de una religiosidad de nuevo orden, más compleja y en la cual se habrían agenciado discursos indígenas asociados al pasado prehispánico y la cuestión indígena colonial.

Sobre lo planteado en el párrafo anterior, pero en relación con los ritos y las festividades y la acción evangelizadora, Alberto Díaz (2011) indica que en ausencia de una eficaz acción evangelizadora en 


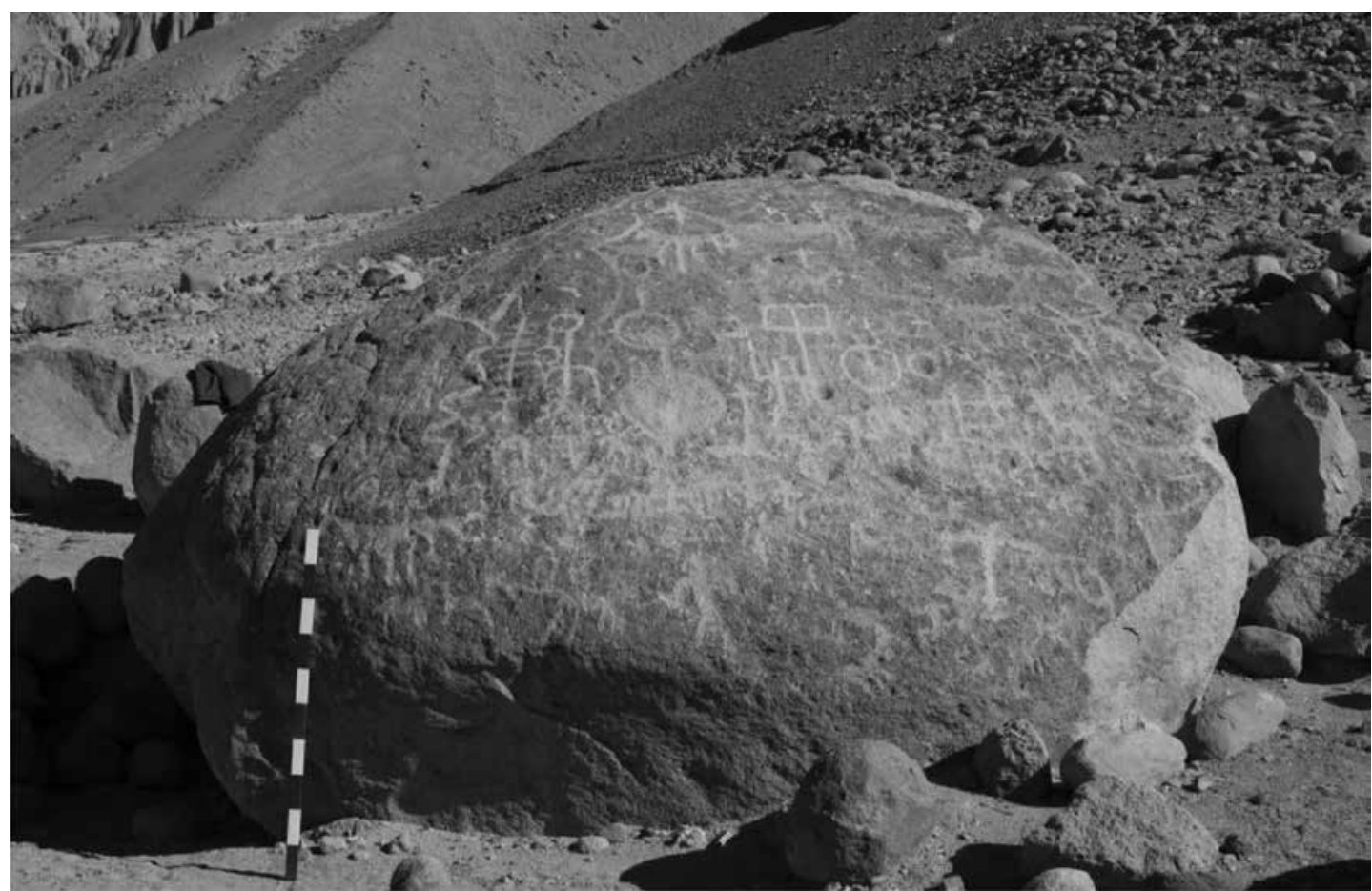

Figura 4. "Huancarane". Panel con múltiples superposiciones de representaciones de origen prehispánico, sobre estas múltiples cruces latinas, unas sobre calvario y otras no. Ubicado en la quebrada de Camarones. Foto: Bosco González Jiménez.

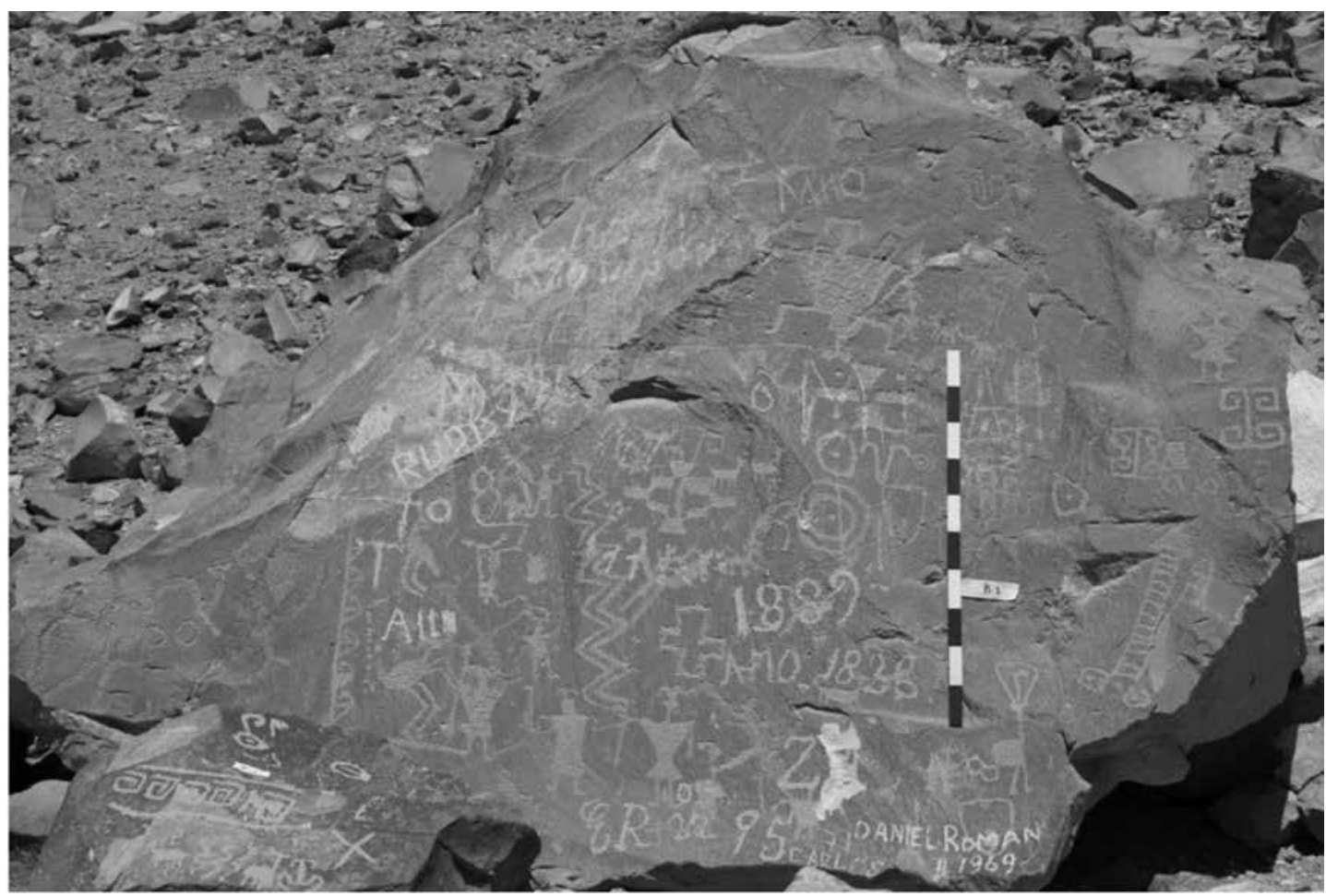

Figura 5. Panel con superposición de motivos prehispánicos, sobre los cuales se superponen cruces, escritura alfabética y fechas, ubicado en el sitio "Angostura de Chiza", sector aledaño a la quebrada de Camarones. Foto: Bosco González Jiménez. 
Tarapacá se habrían constituido autoridades espirituales indígenas en las cuales se habrían agenciado discursos cristianos. Respecto de esto mismo Díaz (2011) y Díaz y Martínez (2014) se refieren a las cofradías como instituciones intermedias que habrían operado entre las autoridades eclesiásticas y los grupos indígenas.

Desde otra perspectiva podemos ver que el uso de motivos cristianos y europeos en contextos Representacionales de origen prehispánico habría servido para continuidad a sistemas de pensamiento y antiguas prácticas "idolátricas" de forma clandestina (Chacama y Santoro, 1993). Es posible asociar esta perspectiva con algunos relatos de cronistas y documentos administrativos de la colonia, en el caso de Huarochirí el doctor Francisco de Ávila, al respecto manifestó en 1608 que "bajo la apariencia cristiana los indios seguían siendo igual de infieles e idolatras que cuando se les conquisto" (Hidalgo \& Díaz, 1985: 77).

Esto se puede evidenciar en el grabado de significantes cristianos en la piedra, muchos de ellos presentes en la decoración de iglesias relativamente cercanas a los lugares en donde estos grabados fueron realizados. En las Figuras 5, 6 y 7 podemos observar una decoración que también se encuentra en los portales de varias de las iglesias de Tarapacá.

Habiendo revisado algunas de las posibilidades de interpretación asociadas a la incorporación de referentes visuales europeos en el arte rupestre colonial, en el siguiente apartado me interesa proponer un camino de reflexión que pretende incorporar a este mismo análisis algunos antecedentes que nos permitan aproximarnos a una lectura que considere la distribución de los sitios con representaciones rupestres en relación con unidades políticas y administrativas de la colonia.

Posee gran relevancia considerar el emplazamiento de los sitios con representaciones rupestres coloniales en el territorio, entendiendo que este está diseñado por las relaciones sociales de producción que han operado y operan en el espacio geográfico, generalmente en el marco de dinámicas de apropiación simbólica del espacio (Bonnemaison, 2004 y Hernández, 2009).

\section{Arte rupestre colonial en Tarapacá, territorio y dinámicas sociopolíticas locales}

Frente a las distintas posibilidades de interpretación enunciadas en los párrafos anteriores me interesa manifestar la importancia que adquiere la evaluación de estas posibilidades de interpretación a partir de un análisis que considere los espacios locales de producción y circulación, dado que esto nos permitirá saber, desde unidades espaciales relativamente acotadas, en qué zonas estos sistemas de comunicación visual continuaron funcionando y con qué intensidad.

Habrían existido zonas con coexistencias antagónicas donde los referentes cristianos y europeos se superpusieron en paneles con representaciones rupestres previas. Habrían existido otras zonas donde estas coexistencias habrían permitido un margen de maniobra mayor a los referentes prehispánicos, logrando poseer espacios de representación significativos en las nuevas soluciones visuales, dado que lo colonial existe ahí donde funciona (Molinié, 1997).

Es por esto que propongo una mirada distribucional que piensa al territorio y el paisaje como un lugar cargado de memoria (Bonnemaison, 1981) el cual está construido selectivamente a partir de etnopercepciones del espacio físico (Álvarez, 1991y Galdames, 1990) que devienen en la formación del territorio y el paisaje como un texto en el cual se inscriben discursos sociales.

Al imponerse un contexto de conquista y colonización las etnopercepciones y procesos de construcción selectiva del paisaje desarrollados en el ámbito local se verán afectadas y transformadas. El conflicto entre formaciones económicas sociales y culturales europeas y locales configurarán nuevos discursos y nuevas maneras de formalizar a estos, en diversos soportes, uno de ellos el paisaje en general y en específico la piedra.

En el presente artículo se ha optado por agrupar los sitios identificados en categorías mayores construidas a partir de la revisión de diversos trabajos sobre la forma en que la Iglesia se habría organizado administrativamente en Tarapacá (Díaz, 2011 y 2014 e Hidalgo, 2004) como también información etnohistórica (Vázquez de Espinoza, 1948).

Basándose en este agrupamiento, una simple distribución espacial (Ver Tabla 2, Gráfico 1 y Mapa 1) comienza a adquirir una característica particular, se comienza a llenar de un sentido social, político e ideológico bastante insinuante.

Según lo que he podido registrar en terreno, en el marco de la revisión bibliográfica y por medio de la conversación con investigadores con una larga trayectoria en el estudio de la arqueología del 


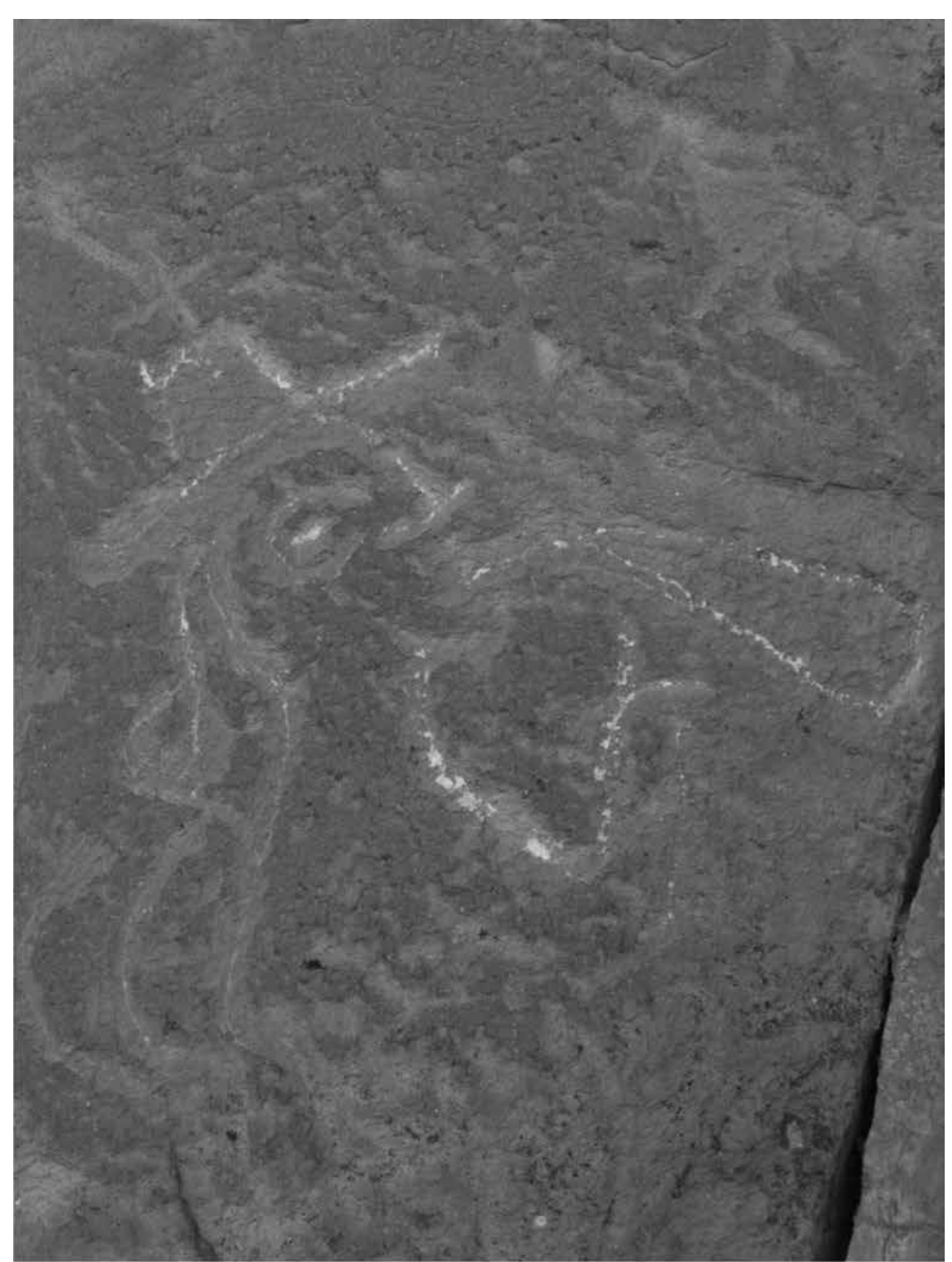

Figura 6. Antropomorfo con sombrero de copa sobre el cual hay una cruz latina, ubicado en el sitio Chillaiza II. Quebrada de Camiña. Foto: Bosco González Jiménez.

norte grande ${ }^{2}$ existirían en lo que fue la doctrina de Tarapacá 11 sitios con presencia de representaciones rupestres coloniales, todos organizados en una vasta extensión espacial, la que posee su límite sur en el río Loa y su límite norte en la quebrada de Camarones.
La forma en que están dispuestos estos sitios en la extensión de Tarapacá sugiere variadas preguntas e indica el punto de inicio de un problema de investigación mayor que dice relación con que tipos de dinámicas sociopolíticas podrían estar asociadas a las diferencias entre un sitio y otro. Los silencios de 
Cuadro 1. Agrupamiento de sitios con representaciones rupestres coloniales en torno al curato de Camiña y de Tarapacá.

\begin{tabular}{lll}
\hline Doctrina & \multicolumn{1}{c}{ Curato } & \multicolumn{1}{c}{ Sitios con motivos rupestres coloniales } \\
\hline & & Huancarane \\
& & Taltape \\
& & Angostura de Chiza \\
& Curato de Camiña & Suca \\
Doctrina de Tarapacá & & Calatambo \\
& & Chillaiza I \\
& & Chillaiza II \\
& & Husaquiña \\
\cline { 2 - 3 } & & Tarapacá 47 \\
& Curato de Tarapacá & Tambillo \\
& & Dupliza \\
\hline
\end{tabular}

las representaciones rupestres coloniales en algunos lugares y la alta frecuencia de presentación de estas en otras zonas de la espacialidad tarapaqueña durante la colonia, nos permiten emplazar algunas preguntas significativas.

¿Cuál es el carácter de esta distribución espacial? ¿Existe una distribución que merezca vincular a esta con el uso de documentos escritos referidos a la administración de la fe en Tarapacá? ¿Nos permite esta distribución de sitios con representaciones rupestres coloniales reflexionar parcialmente sobre la acción evangelizadora y el comportamiento de los grupos indígenas frente a esta? ¿Estuvieron asociados estos sitios con lugares donde se fundaron tempranamente iglesias o se ubicaron en la periferia de los núcleos centrales de acción eclesiástica?

Uno de los primeros elementos que se destaca al analizar la distribución de la función de frecuencia de las representaciones rupestres coloniales agrupadas en torno a los 12 sitios referidos, es que la mayor parte de estas se agrupa en torno al eje norte Huasquiña-Camarones de Tarapacá, agrupándose en este tramo $98 \%$ del total de los motivos identificados para Tarapacá.

Una tendencia similar, pero aun más hacia el límite norte de Tarapacá se desarrolla con el sitio Suca, el cual posee un $35,7 \%$ del total de representaciones rupestres coloniales y que también se encuentra adjunto a Miñita (Ver Mapa 2) poblado que también habría poseído un templo para comienzos del siglo XVII ${ }^{3}$.

Para el caso de Huasquiña también existe la presencia de un templo asociado al sitio, aunque aquí la frecuencia es menor, podemos ver que en relación con el templo existen motivos rupestres coloniales. Resulta importante mencionar que con

Tabla 2. Distribución de frecuencias de presentación de motivos rupestres coloniales.

\begin{tabular}{lcc}
\hline \multicolumn{1}{c}{ Sitio } & Cantidad de registros identificados & Porcentaje asociado \\
\hline Tambillo & 1 & $0,47 \%$ \\
Dupliza & 2 & $0,95 \%$ \\
Tarapaca 47 & 1 & $0,47 \%$ \\
Huasquiña (Chintuma) & 3 & $1,42 \%$ \\
Calatambo & 8 & $3,80 \%$ \\
Chillaiza II & 37 & $17,61 \%$ \\
Chillaiza I & 5 & $2,38 \%$ \\
Suca & 75 & $35,71 \%$ \\
Angostura de Chiza & 25 & $11,90 \%$ \\
Taltape & 9 & $4,28 \%$ \\
Huancarane & 40 & $19,52 \%$ \\
Pampanune & 4 & $1,90 \%$ \\
Curato de Camiña & 206 & $98 \%$ \\
Curato de Tarapacá & 4 & $2 \%$ \\
Total & 210 & $100 \%$ \\
\hline
\end{tabular}




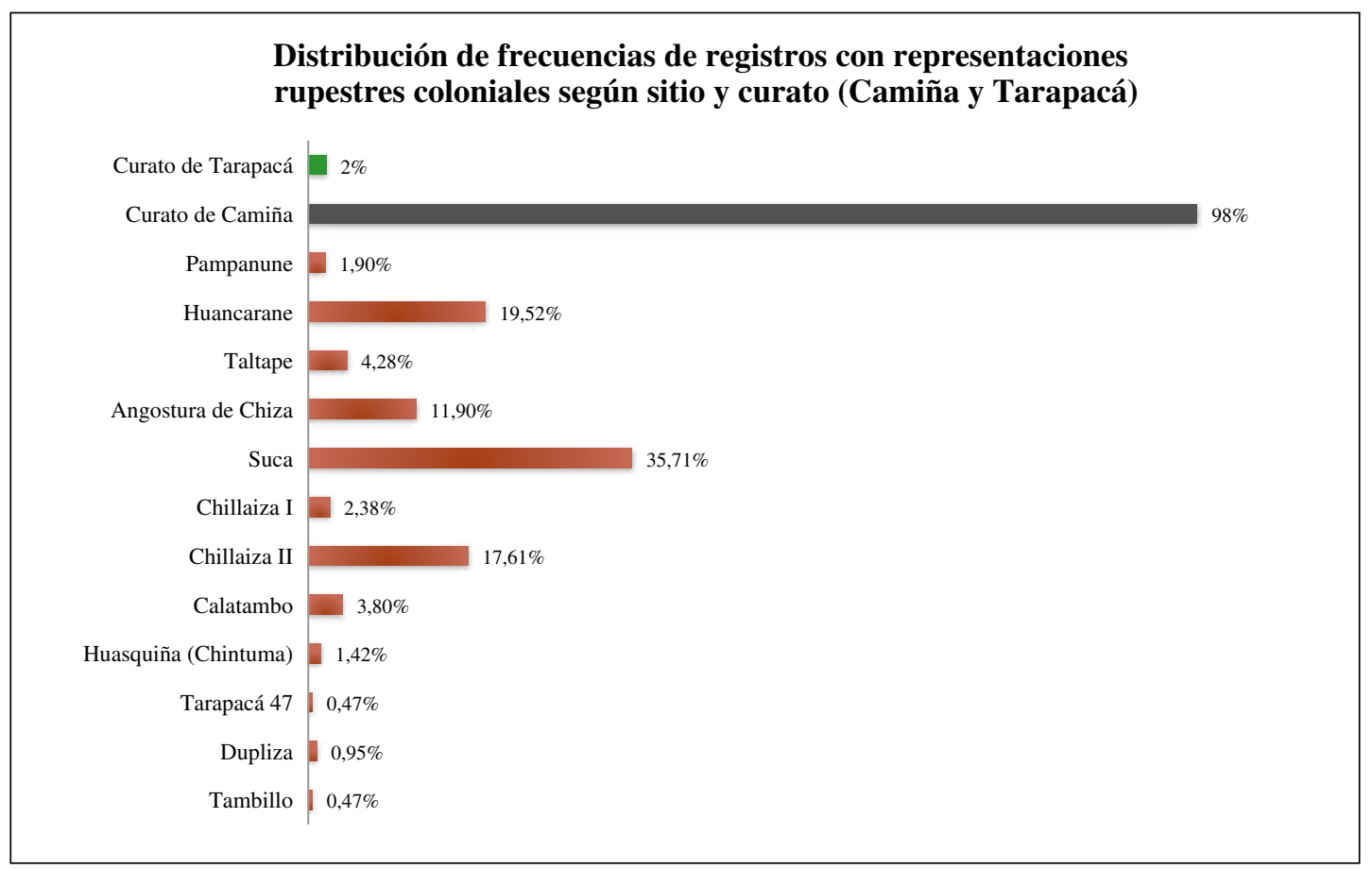

Gráfico 1. Distribución de frecuencia de motivos rupestres coloniales en Tarapacá.

relación a tres del total de los templos mencionados para comienzos del siglo XVII existen sitios con representaciones rupestres coloniales

¿Por qué la gran mayoría de los sitios y la cantidad de representaciones rupestres coloniales se agrupan al interior de lo que fue el curato de Camiña y por el contrario el Curato de Tarapacá posee una presencia marginal de representaciones rupestres coloniales (solo $2 \%) ?^{4}$

El hecho de que el 97,7\% de las representaciones rupestres coloniales de la región se agrupen en torno a lo que habría sido el Curato de Camiña y solo $2 \%$ se agrupen en torno al de Tarapacá nos estaría insinuando algunos elementos para la reflexión etnohistórica, esta simple distribución espacial, al ser sometida a un análisis de la forma en que se habría organizado el andamiaje administrativo de la Iglesia en Tarapacá, nos hace pensar inmediatamente en que el proceso de evangelización y la respuesta de las poblaciones indígenas en la región no habría sido homogéneo ni simultáneo y a la vez nos permite comprender que la simple posibilidad probabilística de que en diferentes lugares, sometidos a desiguales condiciones de control colonial y de evangelización, la suerte de alguno de esos sistemas andinos haya sido distinta (Martínez, 2007: 1984).

\section{Comentarios finales}

Para finalizar me interesa reiterar que el presente artículo no busca responder de forma categórica las preguntas enunciadas, sino más bien enunciarlas y reflexionar sobre ellas en orientación a la construcción de un problema de investigación que vincule el estudio de las representaciones coloniales en espacios locales y aspectos sociopolíticos que caracterizaron a dichas localidades en el periodo colonial.

El problema que intento producir, proceso de producción del cual el presente artículo es expresión, no enfatiza en el estudio detallado de la composición interna de los sitios y los significantes rupestres coloniales; más bien propone abordar la manera en que las representaciones rupestres coloniales se emplazan en un territorio que está diseñado por relaciones sociales y políticas (Bonnemaison, 2004) y es por ello que pienso que la distribución propuesta nos debe remitir a una reflexión mayor que indique antecedentes sobre 


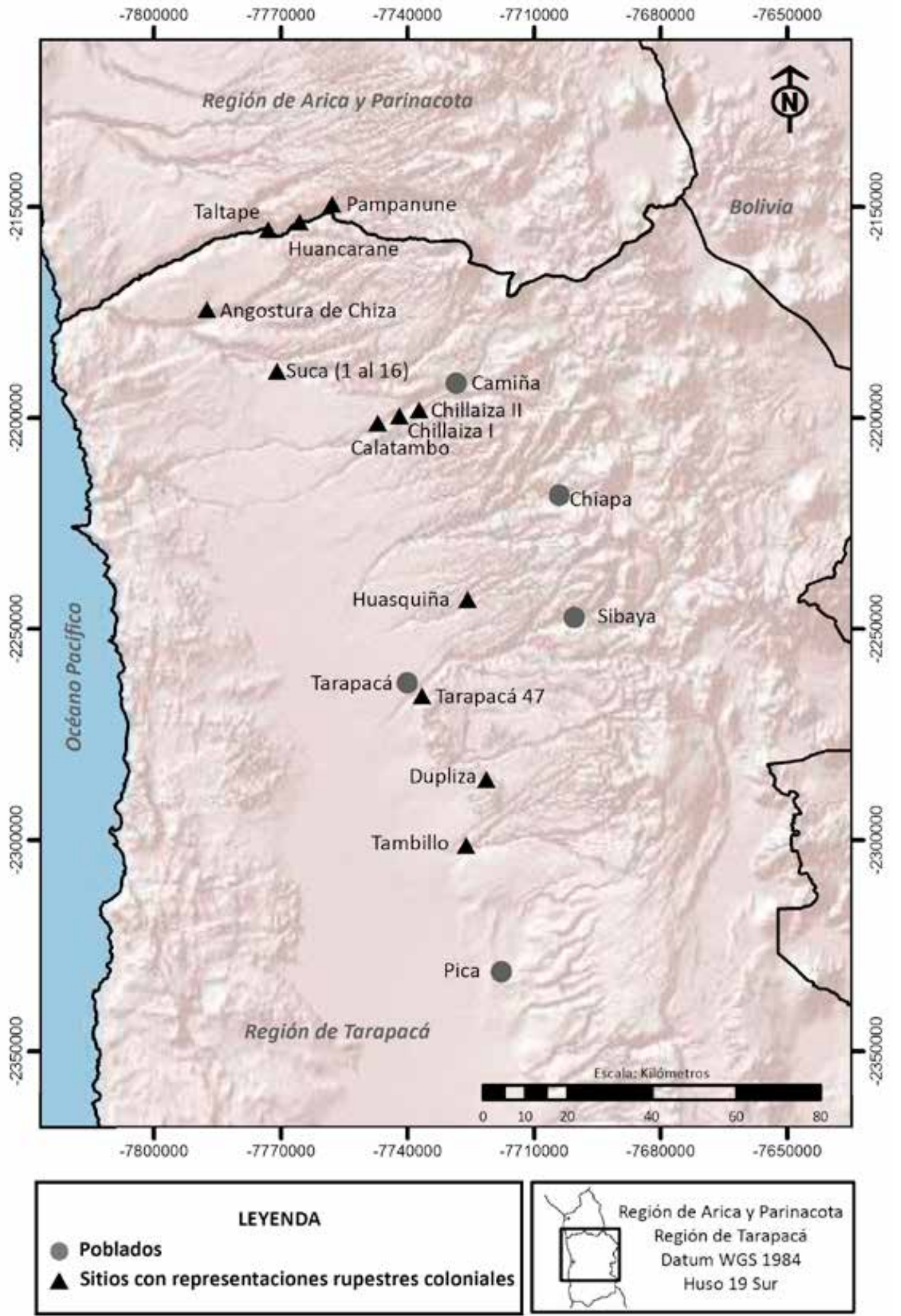

Mapa 1. Distribución en la región de Tarapacá de sitios con representaciones rupestres coloniales. 
los procesos sociopolíticos, los actores indígenas y los agentes colonizadores.

Como un tema a desarrollar en un próximo artículo que necesariamente deberá contribuir a la formación y enriquecimiento del problema de investigación esbozado propongo producir una desagregación de las frecuencias de representaciones rupestres coloniales en tipos de motivos, capaces de indicarnos características aun más particulares de cada uno de estos sitios y de la distribución general también.

Se hace necesario entonces producir un sistema de categorías apropiado para construir criterios de agrupamiento de motivos que den cuenta de dinámicas sociopolíticas asociadas a cada uno de los sitios. Este sistema de categorías debe poseer como centralidad el concepto de coexistencia, desagregándose así en categorías más específicas que denoten la forma en que estas coexistencias significantes se expresaron.

Por ejemplo, en el sitio Chillaiza II ubicado en lo que fue el Curato de Camiña podemos ver que las representaciones cristianas no resultan ser la mayoría, mientras que en otros sitios como Suca, podemos ver que la mayor parte de las representaciones rupestres coloniales existentes en 14 de los 16 sectores que componen el sitio poseen motivos cristianos, pero a la vez en el grupo de los motivos cristianos (cruces) existen algunos que poseen interacción con significantes prehispánicos y otros que no.

Es por esto que me interesa ir cerrando el presente artículo manifestando que nada de lo que aquí se presenta está definido y se considera fundamental orientar el próximo trabajo a la identificación de la distribución de tipos de motivos rupestres coloniales, para identificar en dicho marco qué tipos de discursos específicos se están produciendo y circulando en cada uno de estos espacios.

Junto con lo mencionado anteriormente, considero que este artículo, como también las proyecciones que se propone, colabora con el fortalecimiento de la tesis que plantea la importancia de integrar a los sistemas de comunicación visual como fuentes etnohistóricas con un estatuto no subordinado a la hegemonía de la escritura.

\section{Agradecimientos}

El presente artículo se enmarca en el desarrollo de mis estudios de Doctorado en Historia (M) Etnohistoria en la Universidad de Chile, como también en el desarrollo de los proyectos FONDECYT N 1111063 y FONDART $N^{\circ}$ 52748. Deseo agradecer también los aportes entregados por el Dr. José Luis Martínez, quien ha apoyado mi iniciativa de investigación en todo momento como mi tutor en el doctorado en etnohistoria en la Universidad de Chile. También deseo agradecer al Dr. Alberto Díaz Araya, quien ha apoyado mi proceso de trabajo acogiéndome como investigador asociado del Departamento de Ciencias Históricas y Geográficas de la Universidad de Tarapacá. De la misma manera deseo agradecer la infinita generosidad con la que Luis Briones Morales ha contribuido con mi trabajo, indicándome rutas, sitios y también realizando nutritivos acompañamientos en el trabajo de terreno. Algunas de las fotografías presentadas en el presente trabajo son gentileza de Pablo Méndez Quiros.

\section{Referencias Citadas}

Advis, $\mathrm{P}$.

1994 La Doctrina de Tarapacá en el siglo XVI. Perfil Administrativo-Eclesiástico" en "Tarapacá: Una aventura en el tiempo". Taller de Estudios Regionales, Iquique, Chile. Álvarez, Luis

2011 La categoría de paisaje cultural. Revista de antropología iberoamericana Vol. 6. $\mathrm{N}^{\mathrm{o}}$ 1. Pp. 57-80.

Álvarez, L.

1991 Etnopercepciones andinas: Valles dulces y salados en la vertiente occidental de los Andes. Diálogo Andino 10:9-19.

Arenas, Marco Antonio, Martínez, José, Luis

2009 Construyendo nuevas imágenes sobre los Otros en el arte Rupestre andino colonial. Revista Chilena de antropología visual 13.

Arenas, M. A.; Martínez, J. L.

Los petroglifos del sitio de Tarapacá 47 y su contribución a la Comprensión del arte rupestre colonial andino. Manuscrito en posesión de los autores.
Arenas, M.A. \& Martínez J.L.

2009 Problematizaciones en torno al arte rupestre colonial en las áreas centro sur y meridional andina. En Crónicas sobre la Piedra: Arte Rupestre en las Américas, editado por M. Sepúlveda, L. Briones, J. Chacama, pp. 129-140. Sociedad Chilena de Arqueología, Universidad de Tarapacá, Arica, Chile.

Arenas M. \& Martínez J. L.

2007 Del camélido al caballo: alteridad, apropiación y re significación en el arte rupestre colonial andino. En Actas del VI Congreso de Antropología Chilena. Valdivia.

Berenguer, J.

2004 Caravanas, Interacción y Cambio en el Desierto de Atacama. Sirawi Ediciones, Santiago, Chile.

Bonnemaison J.

2004 La Géographie Culturelle. Geografía Cultural. Curso de la Universidad Paris IV-Sorbona 1994-1997. Ediciones del CTHS, París, Francia. 
Clua, A.; Zusman, P.

2002 Más que palabras: otros mundos. Por una geografía cultural crítica. Boletín de la Asociación de Geógrafos Españoles 34: 105-117.

Chacama, J. L. Briones y Santoro C.

1992 Arte Rupestre pos Hispano: una Aproximación al Problema en el Norte de Chile. En Arte Rupestre Colonial y Republicano de Bolivia y Países Vecinos. Editado por Sociedad de investigación del arte rupestre de BoliviaSIARB, La Paz, Bolivia.

Chacama, J.; Briones, L.; Espinoza, G.

1988-89 El arte mural en las iglesias coloniales de la Primera Región y la tradición pictórica andina en el extremo norte de Chile. Diálogo Andino 7/8: 101-120, Arica.

Cummins, $\mathrm{T}$.

2004 Brindis con el Inca. La Abstracción Andina y las Imágenes Coloniales de los Queros. Universidad Nacional Mayor de San Marcos, Universidad Mayor de San Andrés, Embajada de los Estados Unidos de América, Lima, Perú. Cummins, T.

1993 La representación en el siglo XVI: La imagen colonial del Inca. En Mito y Simbolismo en los Andes. La Figura y la Palabra, editado por H. Urbano, pp. 87-136. CER Bartolomé de Las Casas. Cusco, Perú.

Bouysse-Cassagne, $\mathrm{T}$.

1958 El sol de adentro: Wakas y santos en las minas de charcas y en el lago Titicaca (siglos xv a xvii)". Boletín de arqueología $\mathrm{N}^{\circ}$ 8. Lima: PUCP: 59-97.

Cereceda, V.

2010 Demonio, Barroco y diseños textiles. Memorias del V Encuentro Internacional sobre Barroco. Entre cielos e infiernos, Pamplona, Fundación Visión Cultural/Servicio de Publicaciones de la Universidad de Navarra (Edición digital a partir de La Paz, Fundación Visión Cultural, 2010).

Una extensión entre el altiplano y el mar: Relatos míticos Chipaya y el norte de Chile. Estud. atacam. [online]. 2010, n.40 [citado 2013-04-11], pp. 101-130

Cruz, P.

2006 La puerta de la Wak a de Potosí se abrió al infierno. La Quebrada de San Bartolomé. Anuario de estudios Bolivianos, Archivísticos y Bibliográficos $\mathrm{N}^{\circ} 12$ : 1-40.

Cruz, P.

2006 Mundos permeables y espacios peligrosos. Consideraciones acerca de los Punkus y Qaqas en el paisaje alto andino de Potosí, Bolivia. Boletín del Museo Chileno de Arte Precolombino Vol. 11, No 2: 35-50.

Cummins, $\mathrm{T}$.

1993 La representación en el siglo XVI: la imagen colonial del inca. En Mito y Simbolismo en los Andes. La Figura y la Palabra, editado por Urbano, H. (compilador), pp. 87-136. CER Bartolomé de Las Casas, Cusco, Perú.

Dean, $\mathrm{C}$.

2010 A Culture of Stone; Inka Perspectives on Rock. Duke University Press, Durham, Londres.

Díaz, Alberto

2011 De fiesta en fiesta, de Alférez en Alférez. Fiesta patronal $y$ sistema de cargos religiosos en el norte de Chile. Tesis para optar al grado de Doctor en Antropología. Universidad Católica del Norte. Instituto de investigaciones arqueológicas y museo R.P. Gustavo Le Paige. S.J. San Pedro de Atacama. Chile.
Díaz, Alberto; Chacama, Juan

2012 Procesos de idolatría, discursos nativos y religiosidad en el Mundo andino colonial. Revista Taller de Letras $\mathrm{N}^{\circ} 51$, pp. 53-74

Díaz, Alberto

2014 Martínez, Paula y Ponce Carolina. 2014. Cofradías de Arica y Tarapacá en los siglos XVIII y XIX. Indígenas Andinos. Sistemas de cargos religiosos y festividades. Revista de indias. Volumen LXXIV. No 260, pp. 101-128.

Fernández, G.

1998 Iquiq y anchachu: enanos, demonios y metales en el altiplano. Journal de la societé des americanistes 84: 147-166.

Estenssoro, J. C.

2001 El simio de Dios. Los indígenas y la iglesia frente a la evangelización del Perú, siglos XVI-XVII. Bulletin de l'Institute Francais d'Études Andines 30: 455-474.

Foucault, M.

1992 El Orden del Discurso. Tusquets Editores, Buenos Aires, Argentina. Foucault, M. 2002. La Arqueología del Saber. Siglo XXI Editores, Buenos Aires, Argentina.

Galdames Rosas, Luis

1990 Apacheta la ofrenda de piedra. Diálogo Andino, № 9 , pp. 9-25. Arica-Chile. Universidad de Tarapacá.

Greve, M. E.

1995-1996 Continuidad y cambio en las representaciones icónicas: significados simbólicos en el mundo sur andino. Revista Chilena de Antropología 13: 137-154.

Hernández, M.

2001 Tres momentos, tres contextos, un lugar: Variaciones temporales y contextuales en el arte rupestre de la Quebrada de Humahuaca, Jujuy, Argentina. Boletín del Museo Chileno de Arte Precolombino 8: 59-82.

2006 Incas y españoles a la conquista simbólica del territorio Humahuaca: sitios, motivos rupestres y apropiación cultural del paisaje. Boletín del Museo Chileno de Arte Precolombino 11(2): 9-34

Hidalgo, Jorge

2004 Historia Andina en Chile. Editorial universitaria. Santiago-Chile.

Hosting, R.

2007 Arte rupestre post colombino de la Provincia de Espinar, Cusco, Perú. Hosting, Rainer. Arte rupestre post-colombino en territorio Kana del Cusco, Perú. http://www.rupestreweb. info/postcolom. HTML. 2007

Larraín, $\mathrm{H}$.

1975 La Población indígena de Tarapacá (Norte de Chile), entre 1538 y 1581. Revista Norte Grande 1: 269-300.

Martínez, G.

1983 Los dioses de los cerros en Los Andes. Journal de la societé des americanistes 69: 85-115.

1976 El sistema de los Uywiris en Isluga. Chile: Centro de investigaciones Andinas Isluga. Salazar 1986. Topónimos de Chuani. Versión Digital sin referencia bibliográfica.

Martínez, J. L.

2014 Comparando las crónicas y los textos visuales andinos. Elementos para un análisis. Chungará, Revista de Antropología Chilena 46: 91-113.

2013 De discursos coloniales y textos andinos. A propósito de gente de la tierra de guerra. Chungará, Revista de Antropología Chilena 45. $\mathrm{N}^{\circ}$ 4: 553-560 
2011 Gente de la Tierra de Guerra. Los Lipes en las Tradiciones Andinas y el Imaginario Colonial. Fondo editorial de la Universidad Católica del Perú y Dirección de Bibliotecas y Museos de Chile, DIBAM, Santiago, Chile.

2009 Registros andinos al margen de la escritura: el arte rupestre colonial. Boletín del museo Chileno de Arte Precolombino 14: 9-35.

2009 Registros andinos al margen de la escritura: el arte rupestre colonial. Boletín del Museo Chileno de Arte Precolombino 14: 9-35.

2010 "Mandó a pintar dos aves...": Relatos orales y representaciones visuales andinas. Chungará, Revista de Antropología Chilena 42: 157-167.

2007 Voces e imágenes: La sociedades andinas en los siglos XVI y XVII, y sus lecturas de lo colonial. Actas del VI Congreso Chileno de Antropología. Tomo II.

Muñoz, R. Iván y Mariela Santos Varela

1998 "Desde el Período Tiwanaku al Indígena Colonial: Uso del Espacio e Interacción Social en la Quebrada de Miñita, Norte del Chile". Diálogo Andino 17:69-114.

Odone, $\mathrm{M}$.

1994 La territorialidad indígena y española en Tarapacá colonial (siglos XVI-XVIII): Una proposición. Tesis para optar al grado de Licenciada en Historia. Facultad de Historia, Geografía y Ciencia Política, Pontificia Universidad Católica de Chile, Santiago, Chile.

Salomón, F.

2006 Los Quipocamayos. El Antiguo Arte del Khipu en una Comunidad Campesina Moderna. IFEA-IEP, Lima, Perú. 2005 The Cord Keepers: Khipus and Cultural Life in a Peruvian Village. Duke University Press, Durham, Londres.
1997 Los Quipus y Libros de la Tupicocha de hoy: Un Informe Preliminar. En Arqueología, Antropología e Historia en los Andes, editado por R. Varon; J. Flores, pp. 241-258, I.E.P., Banco Central de Reserva del Perú, Lima.

1994 La textualización de la memoria en la América Andina: una perspectiva etnográfica comparada. América Indígena 54: 229-261.

Sanhueza, C.

2008 Territorios, prácticas rituales y demarcación del espacio en Tarapacá en el siglo XV. Boletín del museo chileno de arte precolombino 13: 57-75.

Urton, G.

2003 La Vida Social de los Números: Una Ontología de los Números y la Filosofía de la Aritmética Quechuas. Centro Bartolomé de las Casas, Cusco, Perú.

Urton, G.

2005 Signos del Khipu Inca: Código Binario. Centro Bartolomé de las Casas, Cusco, Perú.

Urton, G.

1997 De nudos a narraciones. Reconstrucción del arte de llevar registros históricos en los Andes a partir de transcripciones en español de los khipus incaicos. En Saberes y memorias en los Andes. In memoriam Thierry Saignes, editado por Th. Bouysse-Cassagne, pp. 303-323, CREDAL-IFEA, Paris-Lima. Villalobos, S.

1979 La Economía de un Desierto. Tarapacá Durante la Colonia. Ediciones Nueva Universidad, Santiago, Chile, Wachtel, N.

2004 Los indios y la conquista española. En Historia de América Latina. Volumen América Latina Colonial: La América precolombina y la conquista, editado por L. Bethell, pp. 170-204, Cambridge University Press. Editorial Crítica, Barcelona, España.

\section{Notas}

1 Este concepto se plantea en base a las definiciones de Solidaridad Diacrónica y Sincrónica propuesto por Marco Antonio Arenas, 2011.

2 Se hace referencia específica a Lautaro Núñez y Luis Briones.

3 El arqueólogo Iván Muñoz en su texto "Desde el Período Tiwanaku al Indígena Colonial: Uso del Espacio e Interacción Social en la Quebrada de Miñita, Norte del Chile". Diálogo Andino 17:69-114.
4 Según Vásquez de Espinoza la doctrina de Tarapacá habría estado compuesta por el curato de Camiña y el de Tarapacá, los que habrían agrupado los siguientes pueblos: Curato de Tarapacá: Tarapacá, Mamiña Santa María de Guaviña; Limacsiña; Laonzana; Noasa; Coscaya; Sibaya; San Antonio de Mocha y Puchurca. Curato de Camiña: Camiña; Chiapa; Jaiña; Iyalla; Sotoca; Sipisa; Guasquiña; Soga; Guallaga; Miñita; Miñi-Miñi; Camarones; Pisagua; Huancarane. 
